\title{
Rumo ao Estado Nativo com Ressonância Magnética Nuclear
}

João Medeiros-Silva

\author{
Towards the Native State with Nuclear \\ Magnetic Resonance. Biomolecules have \\ evolved to function under specific cellular \\ conditions. Yet, biological molecules are often \\ studied in non-physiological settings due to \\ the enormous technical challenge of studying \\ them within their native media, especially \\ for membrane proteins. Here, cutting-edge \\ solid state NMR methods are described to \\ study membrane proteins and antibiotics \\ at high resolution directly in bacterial \\ membranes. The obtained results indicate \\ the existence of intricate and important \\ structural features that are best perceived \\ when those systems are studied in their \\ physiologically relevant environment.
}

\begin{abstract}
As biomoléculas evoluíram de modo a executar as suas funções sob condições celulares muito específicas. Contudo, estas moléculas são geralmente analisadas em meios químicos pouco fisiológicos. Isto deve-se ao enorme desafio técnico em preservar as condições quimicamente nativas durante o estudo de biomoléculas, particularmente em proteínas membranares. Neste artigo são introduzidos novos avanços em RMN de estado sólido que possibilitam estudar com alta resolução proteínas membranares e certos antibióticos diretamente nas membranas celulares nativas. Esta abordagem ajudou a desvendar propriedades estruturais que são determinantes para o funcionamento destas biomoléculas e que se manifestam num contexto celular.
\end{abstract}

\section{Introdução}

A chave para entender o funcionamento de uma molécula está muitas vezes na sua estrutura. Em biologia estrutural utilizam-se nomeadamente as técnicas de cristalografia de raios-X, crio-microscopia eletrónica e ressonância magnética nuclear para resolver as estruturas das biomoléculas. Porém, cada uma destas técnicas possui certas limitações inerentes que afetam o estudo de sistemas biológicos heterogéneos e insolúveis, tais como proteínas de membrana e outras moléculas associadas a bicamadas lipídicas. A falta de ferramentas eficientes para estudar proteínas membranares limita o potencial de aplicações para estas moléculas que desempenham funções fundamentais nas células e que são os mais proeminentes alvos para a atuação de fármacos [1].

0 estudo de proteínas membranares não é tarefa fácil, recorrentemente as membranas fosfolipídicas têm de ser substituídas por detergentes que acabam por fornecer uma perspetiva simplificada, e não representativa, do que de facto acontece dentro da célula [2]. Para além disso, as propriedades destas proteínas são altamente suscetíveis às características da membrana onde estão inseridas. Levanta-se assim uma questão que até pode ser estendida a todo o tipo de biomoléculas: até que ponto é possível extrapolar as observações obtidas num tubo de ensaio para o que realmente acontece num contexto celular? Para tal, seria necessário investigar as biomoléculas in-cell ou pelo menos num ambiente químico o mais idêntico possível. Com esse objetivo, introduzem-se alguns dos mais recentes desenvolvimentos em espectroscopia de ressonância magnética nuclear que possibilitam estudar proteínas de membrana no seu estado nativo, e as implicações que estes estudos poderão trazer, por exemplo, para o desenvolvimento de novos antibióticos. 


\section{Ressonância magnética nuclear de estado sólido}

A espectroscopia de Ressonância Magnética Nuclear (RMN) é uma ferramenta versátil capaz de fornecer informação sobre as propriedades químicas e estruturais de uma molécula. Essencialmente, em RMN detetam-se transições energéticas do momento magnético do núcleo atómico quando este é sujeito a um campo magnético. Os núcleos de certos elementos químicos, como ${ }^{1} \mathrm{H},{ }^{13} \mathrm{C}$ ou ${ }^{15} \mathrm{~N}$, possuem uma propriedade magnética intrínseca denominada spin. Núcleos com spin comportam-se como ímanes que podem estar alinhados ou desalinhados com um campo magnético externo, tal como quando uma bússola aponta para o polo norte da terra. Quando o momento magnético nuclear transita de um estado energético para outro, o núcleo absorve ou liberta energia caracterizada por uma frequência específica e que pode ser registada num espectro de ressonância magnética nuclear da molécula (Figura 1a). Este espectro de frequências fornece informação química e estrutural acerca da molécula, pois os valores dessas frequências são extremamente sensíveis à estrutura e ambiente químico envolvente a cada um dos núcleos (Figura 1b). Além disso, estes núcleos - tal como ímanes - podem interagir uns com os outros e trocar energias caso estejam espacialmente próximos ou caso compartilhem ligações químicas. Desse modo, é possível correlacionar as frequências dos diferentes núcleos e representá-las em espectros de duas ou mais dimensões (nD). Por exemplo, no espectro $2 \mathrm{D}^{15} \mathrm{~N}-{ }^{-1} \mathrm{H}$ de uma proteína, cada frequência de protão $\left({ }^{1} \mathrm{H}\right)$ está correlacionada com a respetiva frequência de nitrogénio $\left({ }^{15} \mathrm{~N}\right)$ do grupo $\mathrm{NH}$ das ligações peptídicas. Dado que as frequências de ressonância dos núcleos são altamente sensíveis ao ambiente químico, este espectro $2 \mathrm{D}^{15} \mathrm{~N}-{ }^{1} \mathrm{H}$ representa uma impressão digital da proteína (Figura 1c).

Note-se ainda que o tipo de energias envolvidas em RMN está na gama das ondas de rádio, logo este tipo de frequências não compromete o estado da amostra. Portanto, a espectroscopia de RMN apresenta-se como uma técnica não invasiva em que é possível analisar um dado sistema com resolução atómica.

Contudo, a espectroscopia de RMN possui algumas limitações inerentes, especialmente no que respeita à análise de suspensões de partículas insolúveis ou sistemas biológicos relativamente grandes (> $50 \mathrm{kDa}$ ), como é o caso de proteínas inseridas em membranas lipídicas. Basicamente, estas limitações devem-se ao facto destas moléculas, devido ao seu tamanho ou às condições do sistema biológico, girarem lentamente sobre elas próprias na escala molecular. Para ultrapassar este problema, os espectroscopistas giram mecanicamente as moléculas através de rotores orientados a $\approx 54,74^{\circ}$ relativamente ao campo magnético, naquilo que é chamado de Magic Angle Spinning (MAS) em RMN de estado sólido. Quando a amostra gira muito rapidamente ao longo deste ângulo mágico, ocorre um fenómeno em que os operadores quânticos das interações anisotrópicas dos núcleos se anulam, aumentando dramaticamente a resolução dos espectros de estado sólido. Atualmente, as velocidades de MAS atingem vários milhares de rotações por segundo ( $\mathrm{kHz}$ ), i.e. milhões de rotações por minuto. Graças a estes avanços tecnológicos (Figura 2) é agora possível analisar proteínas membranares com alta resolução diretamente dentro das células ou em condições quimicamente nativas $[3,4]$. Note-se que, apesar do nome, RMN de estado sólido não requer que a amostra esteja no estado sólido!

Figura 1 - (a) Transições entre estados de spin desalinhados/alinhados com o campo magnético libertam energia à frequência de ressonância $\left(v_{\mathrm{RMN}}\right)$ do respetivo núcleo, originando um sinal no espectro de RMN. 0 símbolo $\hbar$ corresponde à constante de Planck/2 $\pi$. (b) Representação do espectro $1 \mathrm{D}^{1} \mathrm{H}$ de um resíduo de alanina. Cada $\mathrm{H}$ está associado a uma frequência de ressonância específica que depende da estrutura, ambiente e propriedades químicas envolventes. Note-se que a escala nos espectros de RMN está representada em valores relativos partes por milhão (ppm) em vez de valores absolutos (MHz). Isto facilita a comparação de espectros obtidos por diferentes instrumentos de RMN, pois os valores absolutos das frequências de ressonância variam com o campo magnético enquanto que os valores relativos não variam. Para efeitos de exemplificação do espectro, as linhas foram exageradas e o acoplamento escalar $J$ não foi representado. (c) Espectro $2 \mathrm{D} \mathrm{NH}$ da ubiquitina. No espectro $2 \mathrm{D} \mathrm{NH}$ são correlacionadas frequências de dois núcleos, neste caso ${ }^{1} \mathrm{H}$ e ${ }^{15} \mathrm{~N}$. Cada sinal está associado a um grupo N-H das ligações peptídicas para cada um dos aminoácidos da proteína, possibilitando assim obter informação química e estrutural localizada.

\section{a}
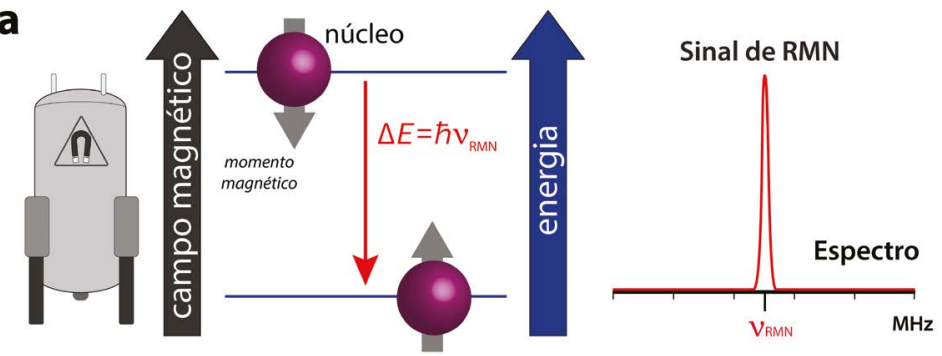

b<smiles>CC(=O)NNC(C)(C)C(C)=O</smiles>

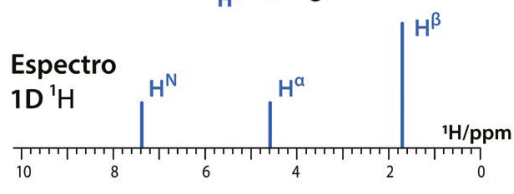



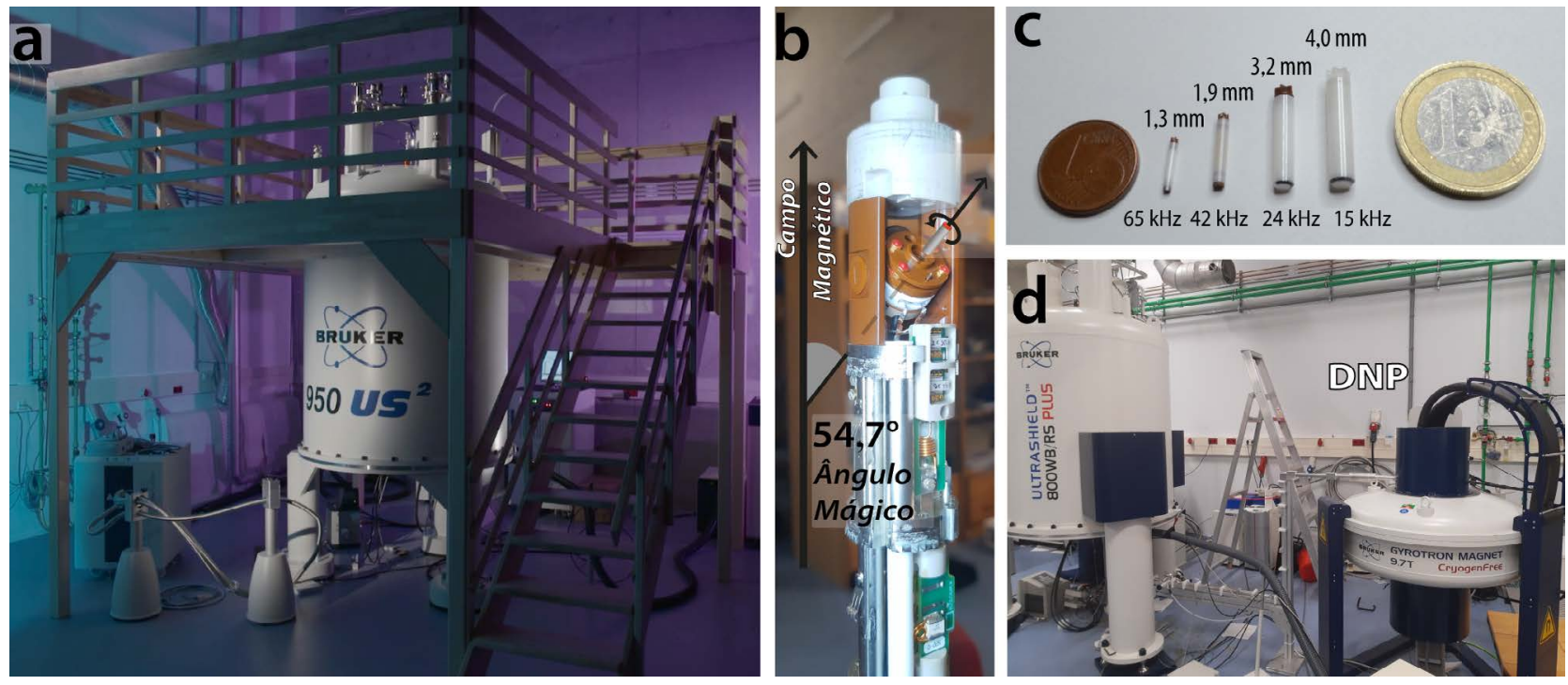

\section{Proteínas de membrana com resolução atómica}

A análise de RMN de proteínas inseridas em membranas celulares, i.e., em condições nativas, é extremamente difícil devido à baixa concentração da proteína na membrana celular e à elevada complexidade do espectro obtido. Com o recente desenvolvimento de campos magnéticos muito elevados (> 25 T, 1,2 GHz em protão), altas velocidades de MAS, polarização nuclear dinâmica (DNP, Figura 2d) e estratégias de deuteração, é agora possível analisar estes sistemas com alta resolução. No âmbito da tese de doutoramento do autor [5], foram desenvolvidas estratégias de deuteração para aumentar a intensidade e resolução dos sinais de protão em proteínas membranares.

0 hidrogénio é o elemento mais abundante em proteínas e possui o núcleo (i.e., protão, ${ }^{1 H}$ ) com o maior momento magnético da tabela periódica dos elementos. Consequentemente, os protões formam extensas redes de interações magnéticas dipolares entre si (Figura 3a) impedindo a leitura eficaz dos espectros das proteínas em RMN de estado sólido. Em contraste, o deutério ( $\left.{ }^{2} \mathrm{D}\right)$ possui um momento magnético mais baixo e não forma interações tão fortes como $0^{1} \mathrm{H}$. Para além disto, $\mathrm{O}^{2} \mathrm{D}$ exibe uma frequência de ressonância magnética diferente de ${ }^{1} \mathrm{H}$. Logo, ao substituir certos protões da proteína por deutério, é possível aumentar dramaticamente a resolução do espectro obtido e selecionar certos domínios da proteína que se pretendem estudar (Figuras 3b e 4).

Figura 3 - (a) Representação da distribuição dos protões (' $\mathrm{H}$, esferas azuis) numa proteína completamente protonada e parcialmente deuterada. A substituição parcial de ${ }^{1} \mathrm{H}$ por ${ }^{2} \mathrm{D}$ nas cadeias laterais dos aminoácidos reduz a densidade das redes de interações dipolares entre protões. (b) Exemplo de um espectro 2D NH de estado sólido com deteção de protão, da ubiquitina parcialmente deuterada (vermelho) e completamente protonada (azul).

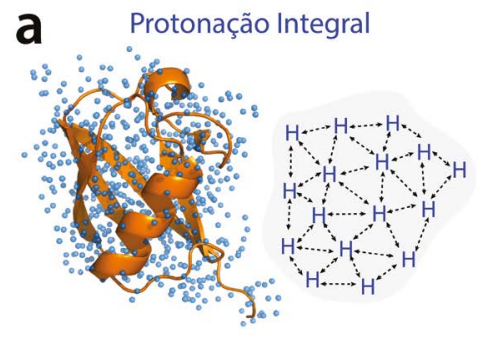

- Laboratório de RMN no Bijvoet Center da Universidade de Utrecht. (a) Espectrómetro de campo magnético ultra-alto de 22,2 T (950 MHz em protão). (b) Sonda de RMN onde se geram e detetam as radiofrequências. 0 rotor é colocado a um ângulo de $\approx 54,7^{\circ}$, denominado de ângulo mágico, relativamente ao campo magnético externo. Este valor mágico advém de que $\left(3 \cos ^{2} 54,74^{\circ}\right)$ $-1 \approx 0$, e se a amostra girar com suficiente rapidez em torno deste ângulo, os valores dos operadores quânticos das interações nucleares anisotrópicas anulam-se. (c) As amostras são introduzidas em pequenos tubos cilíndricos de zircónio (rotores) de diversos diâmetros. Rotores mais pequenos podem atingir velocidades de rotação maiores que resulta numa melhor resolução do espectro obtido, porém a custo da intensidade de sinal devido à menor quantidade de amostra. (d) Dispositivo para experiências de DNP

(Polarização Nuclear Dinâmica). 0 girotrão gera micro-ondas que são transferidas para o espectrómetro onde está inserida a amostra. Esta irradiação por micro-ondas pode gerar um sinal de RMN 600 vezes mais intenso!

(n)

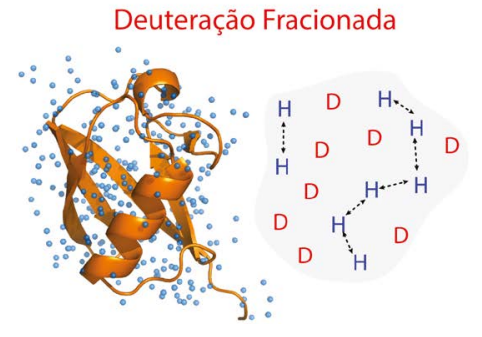

b
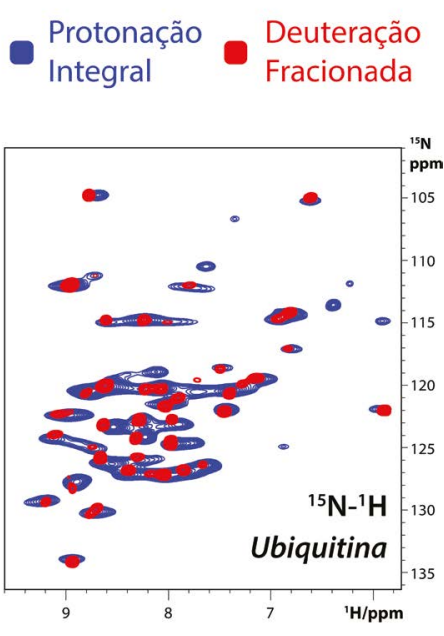
A substituição de ${ }^{1} \mathrm{H}$ por ${ }^{2} \mathrm{D}$ pode ocorrer através da permuta de grupos lábeis com o solvente, e.g. através dos grupos amida das ligáações peptídicas. Já a substituição dos protões a lifáticos requer um caminho diferente, $0^{2} \mathrm{D}$ pode ser introduzido através das fontes de carbono ou outras fontes nutricionais deuteradas presentes no meio de cultura do organismo que produz a proteína de interesse. Exemplos de estratégias de deuteração incluem a Deuteração Fracionada (FD) [6] e a Deuteração Fracionada inversa (iFD) [7] (Figuras 3 e 4), entre outras, dependendo do tipo de sistema a ser estudado [8]. No processo de FD, a proteína é expressa num meio de cultura contendo $D_{2} 0$ como solvente e g'lucose como fonte exclusiva de carbono. Isto resulta na protonação parcial das cadeias laterais dos aminoácidos e na deuteração integral dos grupos amida e $C \alpha$ da cadeia principal. Subsequentemente, os protões poderão ser reintroduzidos nos grupos NH das amidas que estão expostas ao solvente por permuta química em $\mathrm{H}_{2} \mathrm{O}$. Em iFD aplica-se o conceito inverso, utilizando $\mathrm{H}_{2} \mathrm{O}$ no meio de cultura e glucose deuterada. Deste método resulta a protonação dos grupos amida e $C \alpha$ da cadeia principal e deuteração parcial das cadeias laterais.

0 aumento de resolução espectral conferido por estas estratégias permitiu, por exemplo, estudar pela primeira vez o ambiente químico dos protões transmembranares do canal de potássio KcsA (Figura 4) [7,9,10] não só em lipossomas mas também diretamente em membranas celulares de E. coli, neste caso. Estes estudos em membranas explícitas desvendaram finalmente alguns dos mecanismos moleculares responsáveis pelo padrão de condutância de iões nesse canal de potássio. Curiosamente, a razão para o estranho perfil de condutância nestes canais está na dinâmica de movimento dos seus aminoácidos que é altamente afetada pelo ambiente químico [11]. Isto sublinha a importância em estudar não só a estrutura das biomoléculas, mas também a sua dinâmica, que é também acessível por RMN.

\section{Balas mágicas na luta contra superbactérias}

Com a rápida evolução das bactérias multirresistentes, ou superbactérias, é extremamente preocupante o ritmo com que estamos a ficar sem antibióticos, que são autênticos alicerces da medicina moderna. Projeta-se que possam ocorrer dez milhões de mortes relacionadas com infeções de superbactérias já em 2050 [12]. É, portanto, urgente desenvolver mais e melhores antibióticos, capazes de atuar através de mecanismos menos propensos ao desenvolvimento de resistência antimicrobiana.

Alguns antibióticos particularmente eficientes são aqueles que interferem com a regulação da parede celular, que é essencial para a sobrevivência das bactérias. A parede celular é composta por uma camada de peptidoglicano, regulada nas bactérias através do Ciclo do Lípido II (Figura 5). Certos antibióticos ligam-se e sequestram o lípido II, interferindo com a regulação da parede celular
Figura 4 - Espectros 2D NH de RMN de estado sólido com deteção de protão da KcsA em lipossomas de extratos lipídicos de E. coli. Diferentes estratégias de deuteração permitem selecionar diferentes domínios da proteína: (a) Deuteração Fracionada (FD); (b) Deuteração Fracionada inversa (iFD); (c) Deuteração Fracionada inversa, com permuta em $D_{2} 0$. (d) Espectro da KcsA adquirido diretamente em membranas celulares de $E$. coli (magenta), sobreposto com o espectro representado em c) (cinza). Vários resíduos envolvidos no transporte de iões de potássio revelam-se sensíveis à composição da membrana (setas).
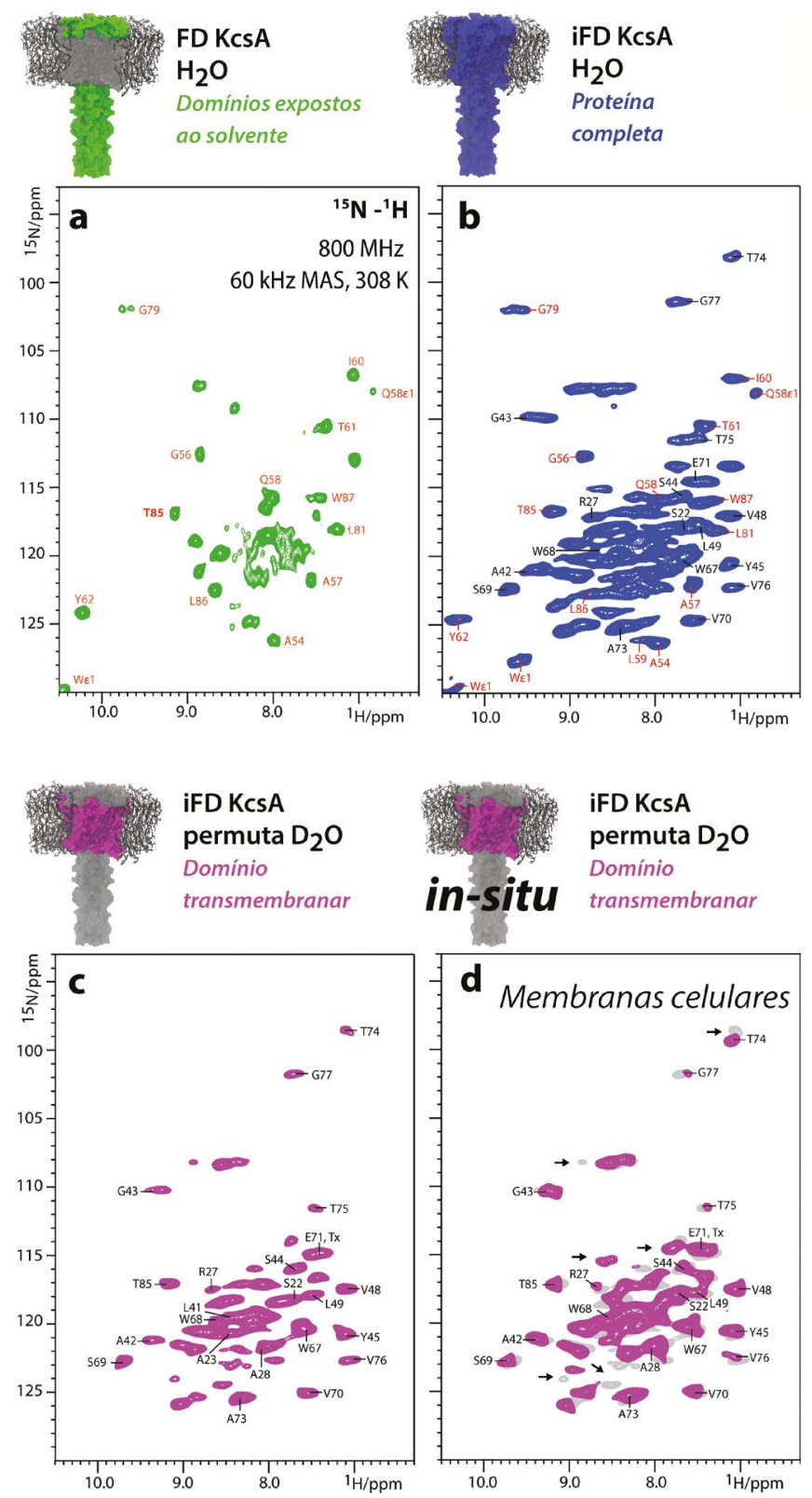

e levando à morte da bactéria. Antibióticos que atuam por essa via são altamente eficazes e menos propícios ao desenvolvimento de resistência antimicrobiana [13] - por esta razão o lípido Il é considerado o calcanhar de Aquiles das bactérias. Alguns exemplos de antibióticos que actuam por esta via são a plectasina, a teixobactina, a tridecaptina A1 e a nisina [14]. 


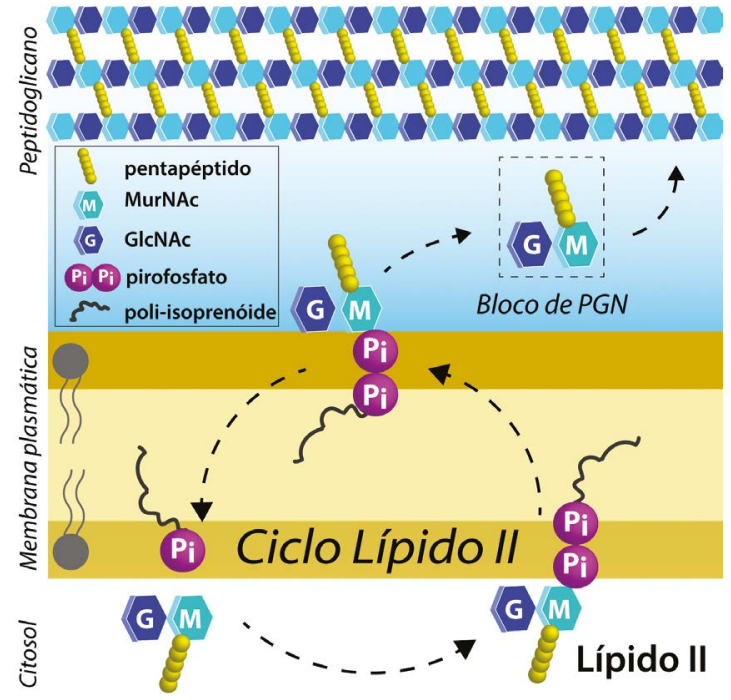

Figura 5 - A construção da parede celular de peptidoglicano depende da regeneração de lípido II através do Ciclo do Lípido II. Do lado interior da membrana plasmática é formado o lípido II, composto por uma subunidade de peptidoglicano e uma cadeia poli-isoprenóide ligadas através de uma ligacção pirofosfato. Subsequentemente, o lípido Il é transportado para o lado exterior da membrana onde enzimas especializadas polimerizam o peptidoglicano a partir dos monómeros transportados. Para simplificar a ilustração, os diversos intermediários e enzimas envolvidos no ciclo foram omitidos. Adaptada da ref. [11].

A nisina (Figura 6a) representa um caso particular pois ao ligar-se ao lípido II forma complexos porosos que rompem a membrana celular das bactérias (Figura 6b). Para além disto, a nisina liga-se especificamente ao grupo pirofosfato do lípido II, portanto a bactéria não pode simplesmente mutar um grupo fosfato e ganhar resistência. De facto, a nisina (também chamada de bala mágica) tem sido utilizada como conservante alimentar (E234) há mais de 50 anos e mostra um certo potencial para uso clínico no combate a superbactérias e biofilmes [15]. Para desenvolver novos derivados antibióticos de uma maneira eficiente e racional, é necessário conhecer a estrutura do complexo poroso nisina-lípido II. No entanto, a formação deste complexo requer uma membrana lipídica que dificulta imenso a sua investigação. Até muito recentemente, as únicas fontes de informação estrutural disponíveis foram obtidas através da utilização de detergentes ou solventes orgânicos. Utilizando RMN de estado sólido, foi agora possível obter dados estruturais do complexo poroso nisina-lípido II em membranas lipídicas (lipossomas), fornecendo a interface de ligação, topologia, estrutura e dinâmica do complexo ao mais alto detalhe [16]. Estes resultados mostram ainda que a informação estrutural previamente obtida em DMSO corresponde a um estado artificial do complexo (Figura 6c), sublinhando a importância em estudar as biomoléculas num meio químico biologicamente representativo.

Embora a utilização de lipossomas constitua um avanço nesta direção, as membranas das células apresentam um ambiente químico muito mais complexo. Existem efeitos de crowding, solvatação, pH, diversos tipos de lípidos, proteínas e outras moléculas que podem influenciar a eficiência do antibiótico. Efetivamente, um dado antibiótico pode exibir atividades bastante distintas perante bactérias diferentes, tornando-se necessário identificar as propriedades responsáveis por estas variações.
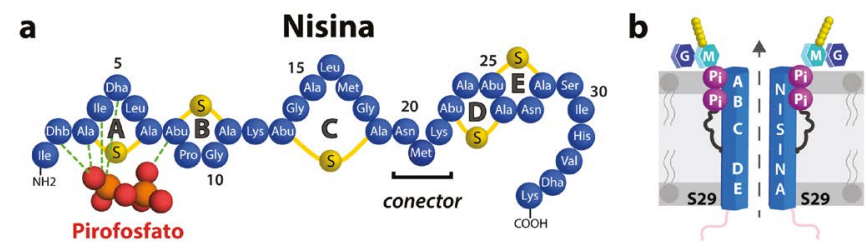

K34-COO K34-COO

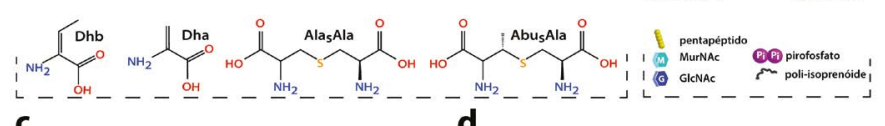

C
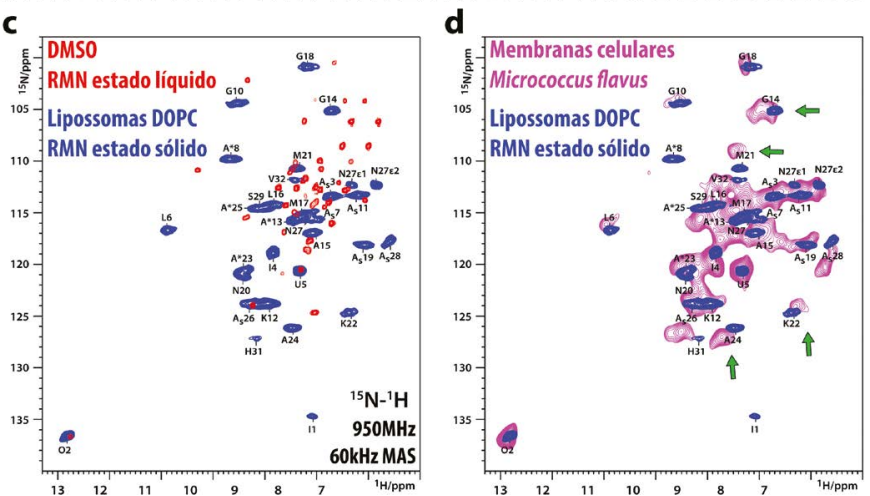

e

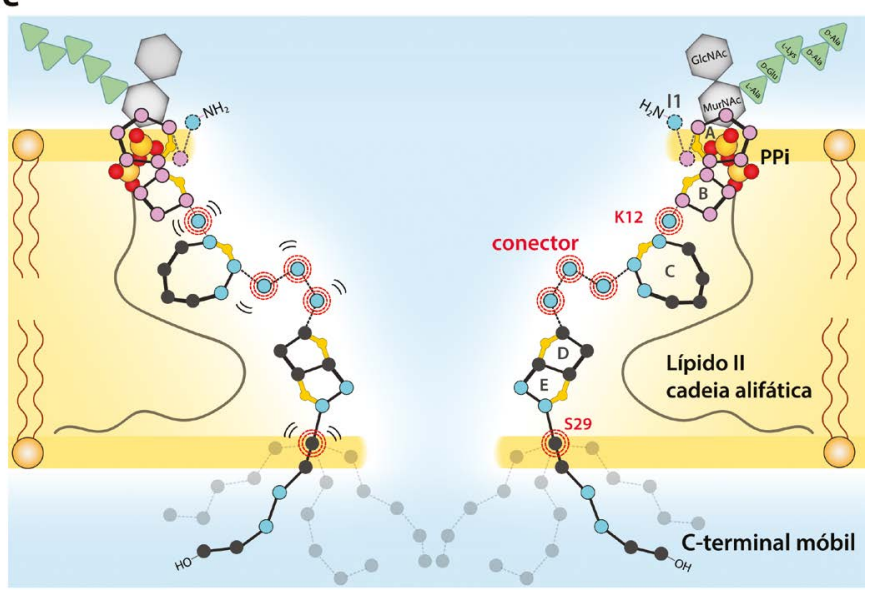

Figura 6 - (a) A nisina é um péptido composto por aminoácidos incomuns tais como desidroalanina (Dha), (Z)-desidrobutirina (Dhb), lantionina $\left(\right.$ Ala $\left._{s} A l a\right)$ e 3-metil-lantionina $\left(\mathrm{Abu}_{\mathrm{s}} \mathrm{Ala}\right)$ que formam cinco anéis (A-E) via ligacções tioéter. (b) Os anéis $A B$ ligam-se ao grupo pirofosfato do lípido II, enquanto que os anéis DE formam o poro. 0 anel $C$ está envolvido na interface de dimerização. (c), (d) Espectro NH do complexo nisina-lípido II em DMSO (vermelho), em lipossomas (azul) e em membranas celulares de Micrococcus flavus (magenta). Os resíduos conectores são sensíveis à composição da membrana (setas). (e) Representação da topologia do poro. Os resíduos plásticos estão destacados com círculos vermelhos. Os resíduos expostos ao solvente estão representados a azul ciano. Adaptada da ref. [16]. 
Utilizando as últimas técnicas de RMN de estado sólido, foi possível estudar com uns escassos ca. 8 nmols o complexo nisina-lípido II diretamente nas membranas celulares de Micrococcus flavus (Figura $6 d)$. Os resultados, suportados por outras medições de permuta ${ }^{1} \mathrm{H} /{ }^{2} \mathrm{D}$ e dinâmica molecular, mostram que os elementos conectores da nisina possuem características plásticas que adaptam a estrutura do poro nisina-lípido II às propriedades da membrana-alvo (Figura 6e). Esta adaptabilidade faz sentido do ponto de vista evolucional, pois possibilita uma ampla e robusta ação do antibiótico para com os diversos tipos de bactérias com membranas diferentes. De facto, verificou-se que a remoção destes elementos conectores previne a formação de poros em bactérias com membranas mais espessas [17]. Curiosamente, estes elementos conectores são também altamente explorados para o design de novos derivados da nisina.

Em suma, o estudo da nisina em condições nativas possibilitou identificar características estruturais até agora desconhecidas e permitiu entender como certas propriedades da membrana influenciam a interação com o antibiótico. Abordagens desta natureza são importantes para o desenvolvimento de novos antibióticos, e para identificar os atributos moleculares que conferem resistência às bactérias.

\section{Conclusão}

Os recentes avanços em RMN de estado sólido possibilitam investigar com alta resolução sistemas membranares complexos, tais como proteínas em membranas celulares. 0 estudo destas biomoléculas no seu estado nativo pode levar à descoberta de novas e importantes propriedades ou nuances estruturais que se manifestam num contexto celular.

\section{Agradecimentos}

A realização deste trabalho não seria possível sem o imenso apoio e dedicação do meu orientador de doutoramento Prof. Markus Weingarth, a quem agradeço imenso. Agradeço também ao Prof. Eurico Cabrita pelas suas discussões e sugestões ao artigo.

\section{Referências}

[1] Y. Arinaminpathy, E. Khurana, D. M. Engelman, M. B. Gerstein, Drug Discov. Today 2009, 14, 1130-1135. DOI: 10.1016/j.drudis.2009.08.006.

[2] C. Chipot, F. Dehez, J. R. Schnell, N. Zitzmann, E. Pebay-Peyroula, L. J. Catoire, B. Miroux, E. R. S. Kunji, G. Veglia, T. A. Cross, P. Schanda, Chem. Rev. 2018, 118, 3559-3607. D0l: 10.1021/acs.chemrev.7b00570.

[3] S. Narasimhan, S. Scherpe, A. L. Paioni, J. van der Zwan, G. E. Folkers, H. Ovaa, M. Baldus, Angew. Chem. Int. Ed. 2019, 58, 12969-12973. DOI: 10.1002/anie.201903246.

[4] R. Damman, S. Narasimhan, M. Weingarth, M. Baldus. Cellular SolidState NMR Spectroscopy. In In-cell NMR Spectroscopy: From Molecula Sciences to Cell Biology; Royal Society of Chemistry, 2020; pp 131-151. DOI: 10.1039/9781788013079-00131.

[5] J. Medeiros-Silva. Towards the Physiologically Relevant State with HighResolution Solid State NMR, Tese de Doutoramento em Molecular Life Sciences, Utrecht University, 2019. dspace.library.uu.nl/handle/1874/385394.

[6] D. Mance, T. Sinnige, M. Kaplan, S. Narasimhan, M. Daniëls, K. Houben, M. Baldus, M. Weingarth, Angew. Chem. Int. Ed. 2015, 54, 15799-15803. DOI: 10.1002/anie.201509170

[7] J. Medeiros-Silva, D. Mance, M. Daniëls, S. Jekhmane, K. Houben, M. Baldus, M. Weingarth, Angew. Chem. Int. Ed. 2016, 55, 13606-13610. DOl: 10.1002/ anie.201606594.

[8] B. Reif. Proton-Detection in Biological MAS Solid-State NMR Spectroscopy. In Modern Magnetic Resonance; Springer International Publishing, 2018; pp 879-910. DOI: 10.1007/978-3-319-28388-3_69.

[9] J. Medeiros-Silva, S. Jekhmane, M. Baldus, M. Weingarth, Solid State Nucl. Magn. Reson. 2017, 87, 80-85. DOI: 10.1016/j.ssnmr.2017.03.003.

[10] K. M. Visscher, J. Medeiros-Silva, D. Mance, J. P. G. L. M. Rodrigues, M. Daniëls, A. M. J. J. Bonvin, M. Baldus, M. Weingarth, Angew. Chem. Int. Ed. 2017, 56, 13222-13227. DOl: 10.1002/anie.201705723.

[11] S. Jekhmane, J. Medeiros-Silva, J. Li, F. Kümmerer, C. Müller-Hermes, M. Baldus, B. Roux, M. Weingarth, Nat. Commun. 2019, 10, 123. DOI: 10.1038/ s41467-018-07973-6.

[12] J. O'Neill. Antimicrobial Resistance : Tackling a Crisis for the Health and Wealth of Nations. Review on Antimicrobial Resistance. 2016, pp 1-16. wellcomecollection.org/works/rdpck35v.
[13] S. F. Oppedijk, N. I. Martin, E. Breukink. Biochim. Biophys. Acta-Biomembr. 2016, 1858, 947-957. DOI: 10.1016/J.BBAMEM.2015.10.024.

[14] J. Medeiros-Silva, S. Jekhmane, E. Breukink, M. Weingarth, ChemBioChem 2019, 20, 1731-1738. DOI: 10.1002/cbic.201800796.

[15] J. M. Shin, J. W. Gwak, P. Kamarajan, J. C. Fenno, A. H. Rickard, Y. L. Kapila, J. Appl. Microbiol. 2016, 120, 1449-1465. DOI: 10.1111/jam.13033.

[16] J. Medeiros-Silva, S. Jekhmane, A. L. Paioni, K. Gawarecka, M. Baldus, E. Swiezewska, E. Breukink, M. Weingarth, Nat. Commun. 2018, 9, 3963. DOI: 10.1038/s41467-018-06314-X.

[17] L. Zhou, A. J. van Heel, O. P. Kuipers, Front. Microbiol. 2015, 6 (JAN). DOI: 10.3389/fmicb.2015.00011.

\section{$>$}

\section{João Medeiros-Silva}

Bijvoet Center for Biomolecular Research, Utrecht University, Utrecht, Países Baixos. Department of Chemistry, Massachusetts Institute of Technology, Cambridge, Massachusetts, USA.

Licenciado e mestre pela Universidade NOVA de Lisboa e doutorado pela Universidade de Utrecht (Países Baixos, 2019). Atualmente é investigador do
Departamento de Química do Massachusetts Institute of Technology. 0 seu trabalho foca-se no desenvolvimento de metodologias em Ressonância Magnética Nuclear de estado sólido para analisar sistemas biológicos complexos ao nível atómico. ORCID.org/0000-0003-3532-4390 jmsilva@mit.edu 